\title{
TEATRO NA ESCOLA E FORMAÇÃO DE ESPECTADORES: UMA PROPOSTA DE APREENSÃO DOS SIGNOS DA CENA
}

\section{Theater in the school and formation of spectators: a proposal for scene's signs seizure}

\author{
Itamar Wagner Schiavo Simões \\ Universidade do Estado de Santa Catarina - UDESC
}

\begin{abstract}
Resumo: Analiso a questão do signo no teatro tecendo relações com indústria cultural e pedagogia do espectador além de apresentar uma ação de formação de público. Utilizo como aporte teórico proposições sugeridas por Ane Ubersfeld, conduzindo a problemática da multiplicidade sígnica da encenação em direção a algumas ideias de Teodor Adorno sobre os modos de percepção do espectador impostos pela indústria cultural, dimensionando uma discussão sobre a obsolescência e a necessidade do teatro na atualidade. Contribui para o debate o estudo de Flávio Desgranges sobre a pedagogia do espectador. Por fim apresento uma ação de formação de público em escolas através do espetáculo Infância.
\end{abstract}

Palavras-chave: signo teatral; indústria cultural; pedagogia do espectador.

Abstract: In this article, I analyze the question of the sign in the theater making relations with the cultural industry and pedagogy of the spectator besides presenting an action of formation of public. I use as a theoretical contribution propositions suggested by Ane Ubersfeld, leading the problematic of the signic multiplicity of the staging towards some ideas of Teodor Adorno on the modes of perception of the spectator imposed by the cultural industry, dimensioning a discussion about the obsolescence and necessity of the theater in the present. It contributes to the debate the study of Flávio Desgranges on the pedagogy of the spectator. Finally I present an action of formation of public in schools through the play Infância.

Keywords: theatrical sign; cultural industry; spectator's pedagogy. 


\section{Linguagem teatral como um} sistema de signos

Em seu valioso estudo sobre a problemática do signo no teatro e da comunicação teatral, Anne Ubersfeld, discorre sobre a importância da leitura do teatro, oferecendo, para tanto, alguns procedimentos semióticos, que para ela, estão vinculados às tensões dialéticas entre a prática textual e a prática da encenação. A comunicação teatral, tal como entendida pela autora, se organiza a partir de um sistema de signos que são elaborados de forma criativa no longo e trabalhoso processo do levar à cena ou encenar. Para ela, a análise semiótica estabelece sistemas de signos textuais que permitem aos profissionais da cena e artistas construir um sistema significante cujo foco destinatário está na figura do espectador (UBERSFELD, 2005, pp. 5-7).

Entendo que esse pressuposto corresponde a um processo de horizontalização das relações entre a cena e a sala que coloca 0 espectador em um lugar de destaque. É através da leitura semiótica que os artistas podem elaborar um sistema significante, que constitui, na encenação, um território cujas fronteiras são alargadas e envolvem o espectador no ato do evento e da comunicação teatral.

\section{Considero}

importante salientar que a autora elabora sua teoria a partir do seu contexto de formação e pesquisa, no qual está inserida a grandiosa tradição clássica francesa de escrita de textos de teatro. No entanto, o vínculo com essa tradição textual, em seu trabalho, se relaciona, também, com toda diversidade e multiplicidade da encenação contemporânea, permitindo a análise destas manifestações. A autora defende os procedimentos semióticos contraargumentando sobre uma possível formalização do texto pela semiótica, o que, segundo ela, é desmentido pela teoria da percepção estética, uma vez que uma leitura mais refinada da multiplicidade das tramas é um elemento lúdico e de prazer estético, além de permitir ao espectador uma atitude criativa de decodificação de signos e de construção dos sentidos. (UBERSFELD, 2005, p. XIV) 
Em direção a esta ideia de construção de sentidos, trago para esta discussão a questão da diversidade e da pluralidade dos signos da encenação. Conforme a autora, aquilo que é criado pela equipe de artistas não possui um sentido único, mas uma pluralidade de sentidos: "o conjunto dos signos visuais, auditivos, musicais criados pelo encenador, decorador, músicos, atores, constitui um sentido (ou uma pluralidade de sentidos) que vai além do conjunto textual" (UBERSFELD, 2005 , p. 3). Além de atestar a diversidade de sentidos que podem ser justapostos ao trabalho teatral, esse pressuposto opera, também, como uma contra-argumentação sobre a ideia da equivalência semântica entre texto escrito e representação.

Ubersfeld diz que a matéria de expressão do texto é linguística, enquanto que a matéria de expressão da representação é múltipla: verbal e não-verbal. Ou seja, existem diferenças estruturais entre a matéria expressiva do texto e a da representação. Esta peculiaridade aponta, na prática da representação, para um trabalho sobre outros materiais significantes. A autora propõe, para clarificar esta questão, o diagrama $\mathbf{T}+\mathbf{T}^{\prime}$-> $\mathbf{P}$, em que, T corresponde ao texto escrito, $\mathrm{T}^{\prime}$ corresponde ao texto da encenação e $P$ à representação; sendo que $T^{\prime}$ é a transformação dos signos não-linguísticos em texto pela equipe de artistas (UBERSFELD, 2005, pp. 7-8). Entretanto, reforço através da fala da autora, que, tratase de um texto com peculiaridades diversas do texto escrito. $O$ que chega até o público é um texto repleto de signos elaborados por materiais diversos, não apenas pelo material linguístico, o que corrobora a não-equivalência semântica.

Posso projetar junto a estas ideias, pensando pela perspectiva da produção de sentidos, uma imagem que contribui para reiterar o lugar concedido ao espectador no processo de criação e elaboração artística. Para tanto, retorno à estrutura sígnica proposta por Ubersfeld (2005, pp. 10-11), caracterizada por uma forma triangular em que o Signo, o vértice 
superior possui suas bases formadas pelo Signifante e Significado.

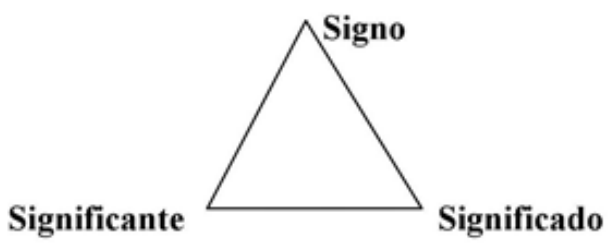

Imagem 01: Tríade Signo-SignificadoSignificante

A construção de sentidos, pelo espectador é um processo de leitura dos signos da encenação, que ocorre a partir de referentes que são os elementos que remetem aos signos no processo de comunicação. Segundo Ubersfeld (2005, p. 16), o referente remete a uma certa imagem do mundo, a uma certa figura contextual dos objetos do mundo exterior. A equipe teatral, durante o trabalho de transformação sígnica, expõe seus referentes para o público convidando-o ao diálogo cuja elaboração se dá através de seus próprios referentes. O convite ao diálogo não é formalizado quando - espetáculo começa, mas neste processo de transformação e elaboração do signo, uma vez que o artista executa esta tarefa para alguém, o que é inerente à prática da comunicação. Ocorre, portanto, um jogo entre referenciais, que requer do espectador a sua própria elaboração de sentidos sobre o que é proposto na cena. Na prática contemporânea e pós-dramática, este jogo é potencializado pela intensificação dos deslocamentos dos referentes e, consequentemente, dos significados propostos pelos artistas, através da figura do signo.

Aqui cabem alguns questionamentos que considero fundamentais. Qual seria a posição do espectador frente a este convite ao diálogo, ele se interessa por este convite? E quanto ao diálogo? O espectador está habituado a este tipo de comunicação? Possui capacidade para efetuar um diálogo nas tramas de uma linguagem que possui suas próprias peculiaridades como a linguagem teatral? Na prática teatral contemporânea, o tensionamento entre significante e significado, ao constituir-se como ferramentas ou procedimentos de encenação, aproxima ou distancia artista e público? 
Indústria Cultural e os modos de percepção do espectador

O processo de esvaziamento das salas de teatro no Brasil, observado por Anatol Rosenfeld desde 0 início dos anos 70 (DESGRANGES, 2010, pp. 19-20), é um dado que se coloca como uma pista para refletir sobre 0 interesse do público pela atividade teatral. Somam-se a este dado, outras estatísticas não muito animadoras e a própria experiência compartilhada dentre muitos artistas e profissionais do teatro, que certificam uma crise que parece não ter fim. Diante da pergunta de qual seria a saída para resolver tal problema, saída esta que deveria ser debatida com o poder público na busca de medidas efetivas relacionadas à formação de plateias, considero importante discorrer sobre uma possível obsolescência da arte teatral frente ao modelo de cultura imposto pela indústria cultural.

Segundo o diagnóstico de Teodor Adorno (2009), a cultura contemporânea está esvaziada de conteúdo artístico por sucumbir à livre iniciativa e ao poder total do capital. As implicações da importância dada ao lucro revelam a falsa identidade do universal e do particular no modelo cultural vigente. $\mathrm{Na}$ medida em que coloca que as artes se definem como indústrias, este autor questiona qual a necessidade social do produto artístico, uma vez que seu texto opera como uma denúncia à manipulação das massas e à alienação da sociedade através da cultura, 0 que subverte, absolutamente, a lógica do bem cultural, de uma obra artística. A cultura e a arte não mais contribuem para a produção de subjetividade, mas buscam o controle da consciência individual, que leva a indústria a estabelecer um padrão ou padrões de consumidor e, por conseguinte, produzir apenas o que é necessário para os padrões definidos. Em suas palavras:

A participação de milhões em tal indústria imporia métodos de reprodução que, por seu turno, fazem com que, inevitavelmente, em numerosos locais, necessidades iguais sejam satisfeitas com produtos estandardizados. [...] Os clichês seriam causados pelas necessidades dos 
consumidores: por isso seriam aceitos sem oposição. $\mathrm{Na}$ realidade, é por causa desse círculo de manipulações e necessidades derivadas que a unidade do sistema cada vez mais impermeável. O que não se diz é que o ambiente em que a técnica adquire tanto poder sobre a sociedade encarna o próprio poder dos economicamente mais fortes sobre a mesma sociedade. A racionalidade técnica hoje é a racionalidade da própria dominação, é o caráter repressivo da sociedade que se autoaliena. [...] Por hora a técnica da indústria cultural só chegou à estandardização e à produção em série, sacrificando aquilo pelo qual a lógica da obra se distinguia da lógica do social. (ADORNO, 2009, p. 6)

Avalio, que, esse processo de manipulação das massas e alienação da sociedade através da cultura tal como proposto por Adorno, contribui para a discussão e o entendimento da obsolescência da arte teatral nos dias atuais. Como colocado anteriormente, a arte teatral se efetiva no diálogo com o espectador, diálogo este que se dá através da expressão de sua subjetividade na decodificação dos signos propostos pela cena. Esta peculiaridade revela uma condição dada ao espectador do teatro muito diferente da condição imposta ao consumidor dos produtos da indústria cultural, conforme pensado a partir das palavras de Adorno.

De acordo com o autor, a indústria cultural proporciona, através das necessidades que cria e de seus produtos estandardizados, um processo de racionalização da sociedade que acaba por a tornar irracional. Ela priva o sujeito da proposta feita pelo esquematismo kantiano de referir a multiplicidade sensível aos conceitos fundamentais. Este é o primeiro serviço ofertado: não há nada mais para o consumidor classificar que o esquematismo da produção já não tenha antecipadamente classificado. A racionalização da sociedade, que se torna cada vez mais irracional, é uma intenção astuta da própria indústria, com vistas a deslanchar o consumo pela massa, através da produção e da oferta em ampla escala em busca do lucro (ADORNO, 2009, pp. 8-9).

A partir desta colocação é possível pensar em um processo de condicionamento de hábitos perceptivos, sobre os quais, os meios de comunicação - grandes parceiros da indústria cultural exercem uma função capital; o que contribui para o debate acerca da 
necessidade da arte teatral nos dias atuais.

Em seu estudo sobre a pedagogia do espectador, Flávio Desgranges (2010) argumenta sobre a influência dos meios de comunicação na modificação dos padrões perceptivos e na sensibilidade do espectador contemporâneo. Os procedimentos de comunicação hegemônicos, a propaganda, a TV, o cinema, utilizados em larga escala pela indústria cultural, pois constituem a própria indústria, ocasionam um hábito mental calcado na ruptura e na fragmentação com justaposição artificial de imagens de abordagem extremamente superficial. Esta abordagem objetiva apenas uma sedução imediata, impedem um contato mais íntimo do espectador e, consequentemente, um mergulho na obra e na narrativa, empreendendo uma atividade interpretativa sobre a obra e a partir dela através de um olhar sobre si mesmo e seu cotidiano pelo afloramento de suas subjetividades e experiências.

Os espectadores consomem uma quantidade de imagens, narrativas

e fragmentos
narrativos, que apesar da
aparente facilidade de
decodificação, impõem uma
fruição superficial, desestimulam a
atitude interpretativa, o esforço
criativo, e a elaboração de juízos
de valor, propondo uma
reflexão desprovida de exigência
estética. A indigestão dos
signos empurrados goela abaixo,
o abuso e banalização da
ficcionalidade, o estilhaçamento
visual, a hiper-fragmentação
narrativa modificam ainda o
campo de percepção do
espectador, influenciando
seu modo de relação com a
espetacularidade e seu horizonte
de expectativa. (DESGRANGES,
2010, p. 38).

Estas ideias, relativas ao condicionamento da percepção e da sensibilidade do espectador, ampliam o campo de discussão sobre as possibilidades e dificuldades da relação estabelecida entre teatro e sociedade em nosso tempo. Por um lado, os produtos da indústria cultural podem ser pensados como fatores que dificultam a relação e uma outra disponibilidade do espectador no evento teatral. Por outro, a atividade teatral em sua constante busca pela instauração de um processo de diálogo que requer uma outra qualidade de presença do 
espectador, possui o potencial de tirar o espectador desse lugar de fruição anestesiada tão caro para a indústria e as mídias de massa, outorgando-lhe um olhar crítico e reflexivo não apenas sobre a obra, mas também sobre si mesmo e sobre o mundo em que vive.

É neste sentido que Desgranges sugere a urgência de uma pedagogia do espectador, a importância de os artistas estarem conscientes de que o teatro é uma experiência artística a ser compartilhada e não um produto a ser vendido para um consumidor alvo. Neste caminho fica clara a importância da produção de espetáculos que não são indiferentes ao público, que reconhecem o espectador como um elemento fundamental do evento teatral, e de ações diretamente ligadas a consolidar este lugar oferecido ao público.

No entanto, afirmo, a partir do autor, que a prática teatral aberta a estas possibilidades, e, de um modo geral, o próprio estágio do teatro contemporâneo atual, podem ser percebidos pelo público habituado às produções audiovisuais hegemônicos como um espaço estranho e difícil de se situar (DESGRANGES, 2010, p. 40). Isso ocorre devido à complexidade dos elementos que constituem uma encenação e; evocando o estudo de Ubersfeld, também, pela própria característica polissêmica de uma encenação, diferentemente do que é disponibilizado pelas produções audiovisuais da indústria cultural.

Neste estágio da discussão a reflexão sobre a pedagogia do espectador pode ser encaminhada na direção da questão do acesso ao teatro, tanto no âmbito do acesso físico quanto linguístico.

\section{A pedagogia do espectador e 0 acesso ao teatro}

Em sua proposta de análise e ação sobre o problema do esvaziamento das salas de teatro, Desgranges estabelece, dentre as ações de formação de público, a diferença entre acesso físico e acesso linguístico. O primeiro está relacionado com todas as ações que promovam a frequentação do espaço teatral, através de estratégias de divulgação e promoção que 
coloquem o espectador diante do espetáculo, tais como: "divulgação competente das peças em cartaz, que atinja público de diversas regiões e classes sociais; promoções e incentivos que viabilizem financeiramente 0 acesso de diferentes faixas de público; condições de segurança; rede de transportes eficiente."

(DESGRANGES, 2010, p. 29).

Percebo que estas estratégias dizem respeito a atitudes que devem ser tomadas não apenas pelos artistas e grupos, mas também pelo poder público, pois estão relacionadas, também, com a própria estrutura organizacional das cidades e ao cuidado da administração pública em estimular o cidadão a frequentar a cidade e os espaços públicos. Outro aspecto importante em relação a esta questão é que, para o espectador, é infinitamente mais fácil acessar os produtos da indústria cultural, seja através de um simples clique no computador, tablet ou smartphone; seja apertando botões do controle remoto da TV, para ficar em dois exemplos. O acesso ao teatro requer outras disponibilidades e atitudes por parte do espectador; tanto física quanto operacional e organizacional, como também a disponibilidade relacionada à aptidão para a leitura das obras, o que caracteriza o acesso linguístico.

Em relação a um dos temas sobre o qual me ocupo neste trabalho - o signo no teatro - a discussão sobre o acesso linguístico é fundamental; embora a questão do acesso físico não seja desnecessária, pois permitiu uma reflexão e articulação com a problemática dos produtos da indústria cultural. $\mathrm{O}$ acesso linguístico está relacionado a outro tipo de encontro entre palco e plateia, um encontro que se efetiva no âmbito da linguagem teatral e do sistema de signos elaborados pelo grupo de artistas.

Segundo Desgranges, a formação do espectador está, também, ligada à sua capacitação para o diálogo com a obra criando o desejo pela experiência artística. Esta capacitação passa por procedimentos que possam criar o gosto pelo debate estético, 
estimulando o espectador a lançar um olhar interpretativo para a obra através de um olhar sobre si mesmo: "assim se contribui para formar espectadores que estejam aptos a decifrar os signos propostos, a elaborar um percurso próprio no ato da leitura da encenação, colocando em jogo sua subjetividade, seu ponto de vista, partindo de suas experiências, da sua posição e do lugar que ocupa na sociedade (DESGRANGES, 2010, p. 30).

Como exposto anteriormente, a partir da leitura de Ubersfeld, a equipe de artistas constrói um sistema de signos que representa um convite a um debate estético a ser realizado com o espectador no evento artístico. O problema está no interesse do espectador em travar esse diálogo desejado, ter capacidade para participar deste processo de comunicação. Para Desgranges, a capacidade de compreensão de uma obra de arte, precisa ser trabalhada, pois: "a capacidade de elaboração estética é uma conquista e não somente um talento natural" (DESGRANGES, 2010, p. 31).
É neste sentido que se fazem necessárias medidas que despertem o interesse do espectador pela atividade teatral tornando-o um frequentador de eventos teatrais. $O$ interesse ocorre na proporção em que ocorre o diálogo com a obra que significa a especialização do espectador que adquire conhecimentos de teatro, familiaridade com os códigos e símbolos veiculados pela cena:

O apreço está diretamente ligado ao grau de intimidade e, apenas entrando em contato com o teatro, seus meandros, técnicas e história - espectador pode reconhecer nele importante espaço de debate das nossas questões, e, principalmente, perceber o quão prazerosa e gratificante pode ser essa relação. (DESGRANGES, 2010, p. 33)

Ante o exposto, fica clara a importância de que os artistas se conscientizem da necessidade de desempenhar ações de formação de plateia. Por outro lado, a formação de espectadores não apenas no campo do teatro, mas nas artes como um todo, não é uma responsabilidade que cabe apenas aos artistas, mas, também, ao poder público, pois o acesso e o fomento à 
cultura é um dever do estado. O diálogo e a experiência artística constituem ferramentas que despertam o espírito crítico, permitindo que o sujeito possa fazer leituras das realidades e debater as questões pertinentes ao seu tempo histórico, olhando para si mesmo, compreendendo-se em relação ao outro e ao seu mundo, o que significa integração e participação social, formação de indivíduos capazes de exercer plenamente a cidadania.

\section{O espetáculo Infância e uma proposta de formação de espectadores}

Após a reflexão realizada até aqui e as relações teóricas estabelecidas, principalmente no que tange à questão da leitura do sistema de signos das obras teatrais e das possibilidades de 0 espectador efetivar essa leitura dialogando com as obras, apresento uma proposta de ação de formação de espectadores através de um espetáculo para a infância.

Este espetáculo foi montado em 2013, a partir do texto de
Thornton Wilder. Nele, acumulei as funções de diretor e ator, esta ultima compartilhada com Cris Fabi e Marcos Mazzucco. Através do fomento do Programa Mais Cultura nas Escolas ${ }^{1}$, o espetáculo foi, no ano de 2016, levado para a E. E. B. Rosinha Campos em Florianópolis/SC. A proposta de trabalho contemplada com o edital deste programa, consistiu em uma ação de democratização do acesso ao teatro, viabilizando o evento teatral em um local de fácil acesso na escola durante o período de aulas; oferecendo, também, ferramentas de mediação que possibilitam a compreensão e a recepção do espetáculo, permitindo o entendimento do funcionamento da cena, contribuindo para o despertar do interesse pela atividade teatral.

O espetáculo encena 0 universo lúdico e fantasioso da infância e, em contrapartida, traz alguns questionamentos relevantes acerca da relação entre pais e filhos,

\footnotetext{
${ }^{1}$ Este programa foi realizado através de uma parceria entre o Ministério da Educação e o Ministério da Cultura e lançado em 2013. O Programa contemplou 5000 propostas em todo o Brasil com o objetivo de aproximar práticas artísticas e culturais do fazer pedagógico das escolas.
} 
tais como: a ausência dos pais pela necessidade do trabalho, a falta de compreensão da criança em relação ao adulto e vice-versa e outras questões relativas ao cotidiano familiar. Os personagens estão inseridos em um mundo repleto de brincadeiras e de sonhos que dialogam com a realidade em que vivem. Uma divertida viagem destas crianças por vários lugares é o fio condutor do espetáculo, viagem que revela a dimensão lúdica do aprendizado da criança.

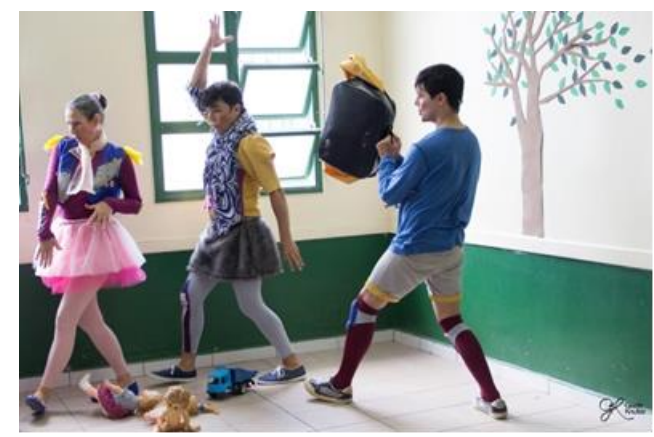

Imagem 02: cena do espetáculo

\section{A temática do espetáculo e a encenação}

Esse trabalho teve como ponto de partida a peça Infância do dramaturgo estadunidense Thornton Wilder. O interesse na encenação deste texto, não originalmente criado para o público que envolve crianças, se baseia no conteúdo atual e reflexivo do mesmo, na relevância dos temas abordados e na importância destes temas para o processo de desenvolvimento da criança diante do mundo que a envolve. Algumas adaptações sobre o texto foram necessárias para favorecer 0 processo de comunicação com 0 público. A adaptação foi realizada em colaboração com uma psicopedagoga de acordo com o objetivo de adequar as questões abordadas pelo texto e pela cena ao nível intelectual e cognitivo das crianças.

No espetáculo os personagens apresentam de forma divertida 0 universo lúdico $\mathrm{e}$ fantasioso da infância e também questionam o comportamento dos pais, revelando a fragilidade desta relação. A encenação está centrada na possibilidade de permitir ao espectador infantil ver a si mesmo através de um novo olhar, de contextualizar e refletir sobre questões éticas e comportamentais relevantes para o conhecimento do 
sujeito diante de si e do meio em que vive.

A montagem foge dos padrões de histórias infantis clássicas muitas vezes abordadas de forma romântica, ingênua e distante da realidade e do cotidiano do público infantil. Os personagens não são derivados de algo já existente como personagens de filmes, desenhos, jogos e quadrinhos feitos para crianças.

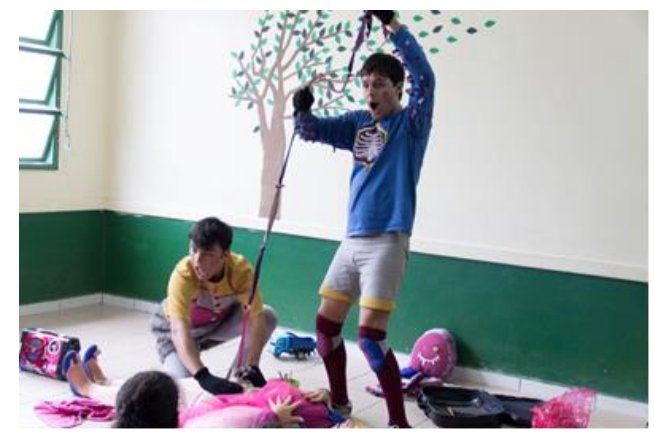

Imagem 03: cena do espetáculo

Uma das principais referências para a estética visual do espetáculo é o movimento de arte contemporânea Toy Art, que envolve manifestações de culturas urbanas como o design, a ilustração, a pintura, o grafite e a moda. Os bonecos produzidos pelos artistas da Toy Art possuem características visuais infantis e expressam um posicionamento crítico ou irônico de seu criador sobre diversos assuntos. Esses bonecos não são propriamente brinquedos infantis, mas possuem um aspecto lúdico que evoca um universo de fantasia, além de uma expressão provocativa, por suas características agressiva, grotesca, ou irônica (OFUGI, 2009, p. 11). O interesse por este referencial surgiu da motivação em criar um conceito estético de conteúdo artístico significativo e atrativo para os espectadores, apartando, também dos referenciais normalmente utilizados pelas mídias de massa.

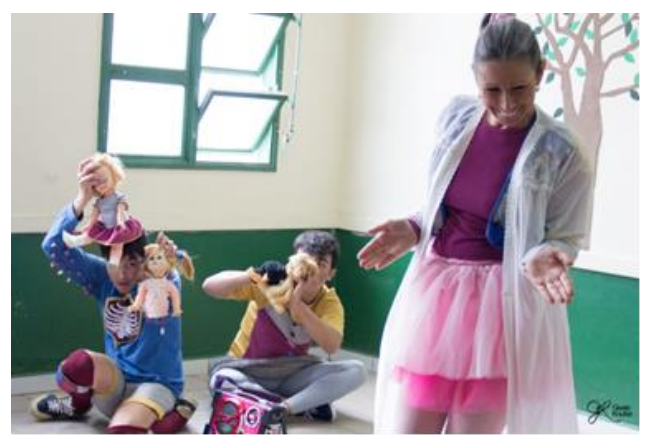

Imagem 04: Cena do espetáculo 


\section{A ação de formação de espectadores}

A ação consistiu em apresentações do espetáculo para todas as turmas do ensino fundamental I e realização de uma oficina de teatro após cada apresentação. Em cada oficina foi proposta uma experiência artística a partir de alguns procedimentos pedagógicos em que os espectadores puderam interagir com o espaço teatral e os elementos cênicos do espetáculo, vivenciando algumas das brincadeiras dos personagens da peça assistida e experimentando parte do processo criativo dos atores. A proposta foi de oferecer doses de criação artística, permitindo a leitura criativa e a apropriação dos signos veiculados pela cena, a criação de seus próprios significados e a experimentação de algumas das referências do processo criativo dos atores, gerando aprendizado e alguns conhecimentos acerca de aspectos da linguagem teatral. A ação intensifica a experiência de assistir, trazendo intimidade com a linguagem com o potencial de despertar o interesse e instaurar o hábito de ir ao teatro. Foram realizadas, ao todo, cinco apresentações e cinco ações de formação de espectadores.
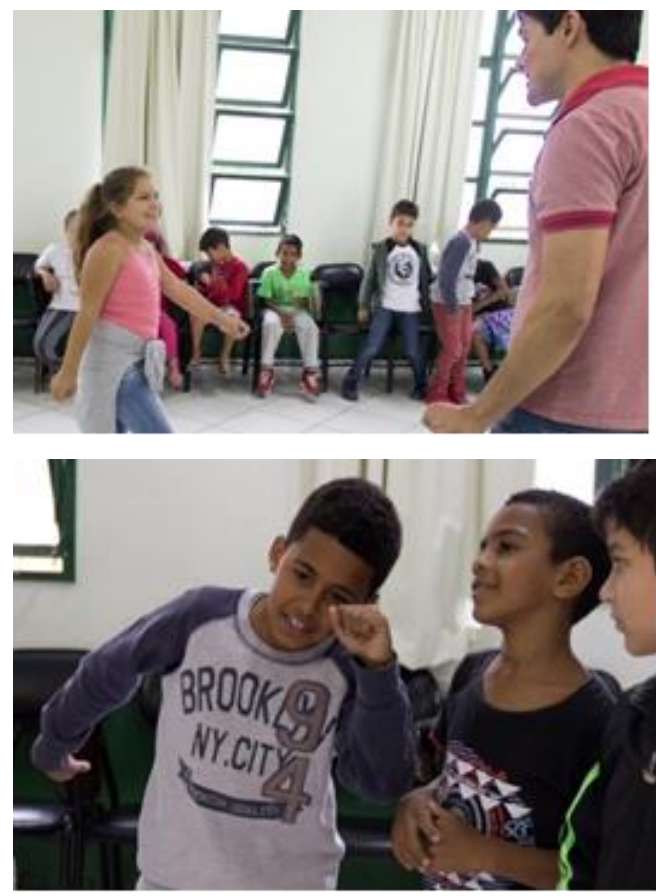

Imagens 05 e 06: Ação de formação de espectadores

\section{Metodologia da ação de formação} de público

- Divisão do grupo de espectadores em três turmas.

- Cada turma participa de uma oficina com uma temática diferente e cada oficina é coordenada por um dos atores, em salas diferentes, 
de modo que elas ocorriam simultaneamente.

- Oficina 1: Criando os brinquedos dos personagens

Esta oficina tem como referência uma cena do espetáculo em que os personagens retiram diversos objetos de dentro do baú, brincam com esses objetos e os separam para levar para a viagem. Os objetos não são efetivamente brinquedos, mas se transformam em brinquedos através do imaginário e da ação dos personagens.

- Momento 1: Apresentação de cada integrante da turma: em um círculo, cada integrante vai até o centro da roda e diz o seu nome acompanhado de um gesto/ação/movimento.

- Momento 2: Observação de cada objeto, prestando atenção em sua forma, imaginando em quê esse objeto poderia se transformar.

- Momento 3: Experimentação dos diferentes objetos transformando-os em brinquedos.

- Momento 4: Improvisação de uma pequena cena retirando

os objetos do baú,
transformando-os
brinquedos e brincando com
eles

- Oficina 2: A primeira viagem de ônibus

Esta oficina tem como referência a cena em que os personagens iniciam sua viagem a bordo de um ônibus e criam movimentos corporais e sons vocais que expressam 0 deslocamento do ônibus.

- Momento 1: Apresentação de cada integrante da turma: em um círculo, cada integrante vai até o centro da roda e diz o seu nome acompanhado de um gesto/ação/movimento

- Momento 2: Criação de formas corporais a partir de estímulos verbais: Inicialmente 0 oficineiro demonstra o propósito da dinâmica, falando um estímulo e criando duas formas para este estímulo. As crianças realizam a dinâmica a partir dos estímulos "nuvem", "vento" e "trovoada", criando duas formas para 
cada estímulo e escolhendo uma delas.

- Momento 3: Experimentação das formas corporais, criando um movimento repetitivo e um som para cada forma.

- Momento 4: Improvisação um deslocamento no espaço com os diferentes movimentos e sons criados, alterando ritmos
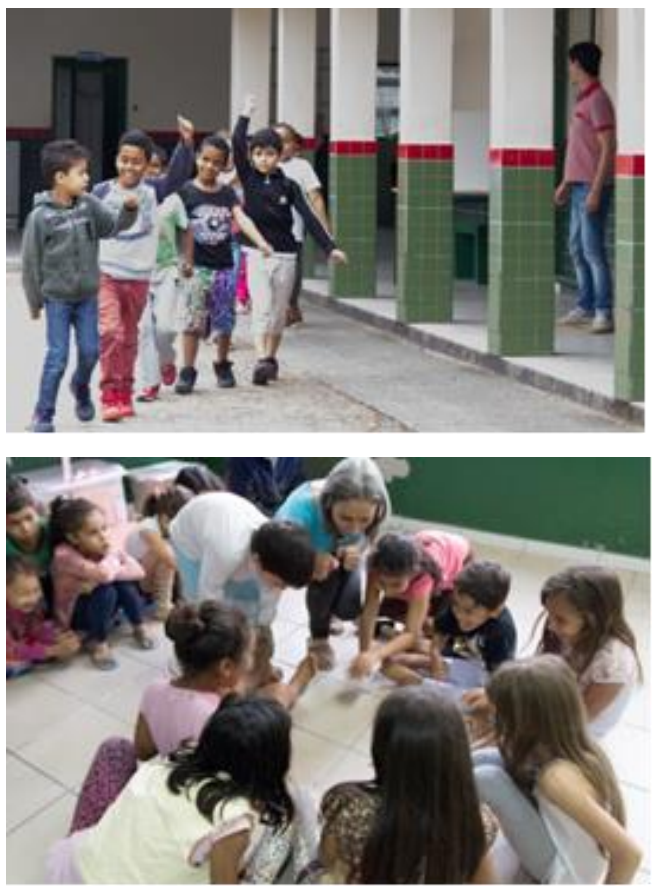

Imagens 07 e 08: Ação de formação de espectadores

- Oficina 3: A segunda viagem do ônibus

Esta oficina tem como referência a cena em que os personagens, depois de passar por vários lugares, retomavam a viagem de ônibus criando movimentos corporais. Os movimentos funcionam como uma partitura de dança, a ser realizada com uma música da trilha sonora do espetáculo.

- Momento 1: Apresentação de cada integrante da turma: em um círculo, cada integrante vai até o centro da roda e diz o seu nome acompanhado de um gesto/ação/movimento.

- Momento 2: Criação de formas corporais a partir de estímulos verbais: Inicialmente 0 oficineiro demonstra o propósito da dinâmica, falando um estímulo e criando duas formas para este estímulo. As crianças realizam a dinâmica a partir dos estímulos "correnteza", "onda" e "redemoinho", criando duas formas para cada estímulo e escolhendo uma delas.

- Momento 3: Experimentação de cada forma corporal criando movimentos para cada uma, intercalando estes 
movimentos criando um modo de dançar.

- Momento 4: Experimentação dos movimentos com a música da trilha sonora do espetáculo e improvisação de um deslocamento no espaço, alternando ritmos.

- Compartilhamento dos processos criativos de cada turma no espaço de apresentação do espetáculo com a trilha sonora do mesmo.

\section{Considerações finais}

As ações deste projeto foram inspiradas nas ideias expostas sobre a questão da pedagogia do espectador, buscando contemplar, tanto a questão do acesso físico como a do acesso lingüístico, levando o espetáculo até o público e oferecendo uma experiência que contribui para a formação do olhar e para aquisição de ferramentas lingüísticas para 0 diálogo e 0 interesse pela atividade teatral.

A abertura para o espectador no evento teatral reside sobre 0 caráter múltiplo dos signos propostos no texto da encenação e sobre a não equivalência semântica entre texto escrito e texto da encenação, convidando 0 espectador para 0 diálogo. No caso desta montagem, o processo de elaboração sígnica gerador do texto da encenação foi intensificado.

Primeiro porque havia uma proposta de encenação que acentuasse 0 universo lúdico e fantasioso da infância contido no texto de Wilder, para equilibrar o posicionamento crítico das personagens das crianças frente ao comportamento dos pais no seio das relações familiares. Segundo por causa das muitas adaptações realizadas em parceria com uma psicopedagoga frente às especificidades cognitivas do público.

O diálogo se processa no jogo entre os referenciais da cena e de cada espectador em suas múltiplas realidades e a experiência do fazer intensifica esse processo de leitura e elaboração sígnica. As ações do projeto caminharam na direção de permitir que o espectador não se comporte apenas como receptor de discursos, mas também como elaborador; atitude que 0 
convida a ocupar o seu lugar no teatro, ação simbólica que também o convida a ocupar o seu lugar no mundo.

Recebido em 26/06/2018

Aceito em 28/08/2018

\section{Referências Bibliográficas}

ADORNO, Teodor. Indústria Cultural e Sociedade. São Paulo: Editora Paz e Terra, 2009.

DESGRANGES, Flávio. A Pedagogia do Espectador. São Paulo: Editora Hucitec, 2010.

OFUGI, Marina. Toy Art: conceitos e contextualização dos brinquedos de design na esfera da arte e da indústria cultural. Trabalho de Conclusão de Curso de Comunicação Social da Faculdade de Tecnologia e Ciências Sociais Aplicadas - UniCEUB. Brasília, 2009. Disponível em: <http://repositorio.uniceub.br/bitstrea m/123456789/1923/2/20515745.pdf> . Acessado em 10/06/2018

UBERSFELD, Anne. Para ler o teatro. São Paulo: Editora Perspectiva, 2005. 